\section{(A) Check for updates}

Cite this: Dalton Trans., 2022, 51 3604

Received 17th November 2021 Accepted 25th January 2022

DOI: $10.1039 / \mathrm{d} 1 \mathrm{dt} 03897 \mathrm{~d}$

rsc.li/dalton

\title{
Core-shell and heterostructured silver-nickel nanocatalysts fabricated by $\gamma$-radiation induced synthesis for oxygen reduction in alkaline media $\uparrow$
}

\author{
Yi Yang, (D) *a Gerard Montserrat-Sisó, (DD b Björn Wickman, (DD b \\ Pavel Anatolyevich Nikolaychuk (D) ${ }^{c}$ and Inna L. Soroka (D) *a
}

\begin{abstract}
To reach commercial viability for fuel cells, one needs to develop active and robust Pt-free electrocatalysts. Silver has great potential to replace $\mathrm{Pt}$ as the catalyst for the oxygen reduction reaction (ORR) in alkaline media due to its low cost and superior stability. However, its catalytic activity needs to be improved. One possible solution is to fabricate bimetallic nanostructures, which demonstrate a bifunctional enhancement in the electrochemical performance. Here, two types of bimetallic silver-nickel nanocatalysts, core-shells $(\mathrm{Ag}(\mathrm{aNiO})$ and heterostructures $(\mathrm{Ag} / \mathrm{Ni})$, are fabricated using $\gamma$-radiation induced synthesis. The Ag@NiO nanoparticles consist of an amorphous, NiO layer as a shell and a facetted crystalline Ag particle as a core. Meanwhile, the Ag/Ni heterostructures comprise Ag particles decorated with $\mathrm{Ni} / \mathrm{Ni}$ (oxy-hydro)-oxide clusters. Both materials demonstrate similar and increased alkaline ORR activity as compared to monometallic catalysts. It was revealed that the enhanced catalytic activity of the core-shells is mainly attributed to the electronic ligand effect. While in the Ag/Ni heterostructures, a lattice mismatch between the Ni-based clusters and Ag implies a significant lattice strain, which, in turn, is responsible for the increased activity of the catalyst. Also, the Ag/Ni samples exhibit good stability under operating conditions due to the existence of stable $\mathrm{Ni}^{3+}$ compounds on the surface.
\end{abstract}

\section{Introduction}

Anion exchange membrane fuel cells (AEMFCs) are considered as next generation fuel cells and show great potential to be an alternative to acidic proton exchange membrane fuel cells (PEMFCs). ${ }^{1}$ Alkaline conditions in AEMFCs allow the usage of less expensive, Pt-free catalysts for the oxygen reduction reaction (ORR). ${ }^{2}$ Potential candidates include many abundant transition metals, the use of which drastically reduces the cost per kilowatt of power in fuel cell devices. ${ }^{3}$ One such candidate is $\mathrm{Ag}$, whose market price is approximately 50 times lower than that of Pt and 90 times lower than the price of $\mathrm{Pd}$ and $\mathrm{Au}^{4}$ Moreover, as it has been reported in a number of studies, $\mathrm{Ag}$

\footnotetext{
${ }^{a}$ Applied Physical Chemistry, Department of Chemistry, School of Engineering Sciences in Chemistry, Biotechnology and Health, KTH Royal Institute of Technology, S-100 44 Stockholm, Sweden. E-mail: yiyan2@kth.se

${ }^{b}$ Chemical Physics, Department of Physics, Chalmers University of Technology, 412 96 Gothenburg, Sweden

'Institute of Environmental and Agricultural Biology (X-BIO), University of Tyumen, 625003 Tyumen, Russian Federation

$\dagger$ Electronic supplementary information (ESI) available. See DOI: 10.1039/ d1dt03897d
}

can display high electrocatalytic activity for the ORR in alkaline media. ${ }^{5-7}$ Like Pt, the ORR on the silver surface takes place via a pseudo four-electron transfer pathway. The Tafel slope for the Ag catalysts shows a similar trend to that for Pt, thus, indicating the similarity of ORR kinetics for both metals. ${ }^{8,9}$ In addition, $\mathrm{Ag}$ has good electrochemical stability in alkaline solutions according to the Pourbaix diagram. ${ }^{10}$

It is believed that there are two dominant factors that govern the ORR activity in alkaline media: (i) adsorption strength of the oxygen species on the catalyst surface and (ii) $\mathrm{O}-\mathrm{O}$ bond breakage tendency. ${ }^{11,12}$ However, since the d-band of $\mathrm{Ag}$ is completely occupied, it is difficult for pure silver to provide unpaired electrons from the d-band to form bonds with oxygen, thus resulting in low oxygen coverage. ${ }^{13}$ Meanwhile, Ag shows slow kinetics of the $\mathrm{O}-\mathrm{O}$ bond split. ${ }^{12}$ These factors result in much lower ORR activity of Ag than that of e.g., Pt. One way to improve the ORR activity of $\mathrm{Ag}$ is to decrease the d-band charge density, thus, lowering the d-band center. This can be done by introducing another metal with low d-band occupancy, for example, $\mathrm{Ni}^{14}$ and $\mathrm{Co}^{10}$ to form bimetallic composites.

$\mathrm{Ni}$ is one of the most widely used elements in metal-based catalysts. ${ }^{15}$ It is known for its low d-band occupancy and high 
alloying ability with some noble metals and many transition metals. As shown in the literature, the alloying effect may contribute to the enhanced catalytic activity of the constituents. ${ }^{10,16} \mathrm{Ag}$ and $\mathrm{Ni}$ are thermodynamically immiscible, which makes it quite difficult to form alloys. However, some studies on $\mathrm{Ag}-\mathrm{Ni}$ alloy nanomaterials can still be found. ${ }^{17,18}$ As shown in the literature, during synthesis and operation, metastable AgNi alloys may undergo structural reorganization followed by atomic segregation. ${ }^{9,20}$ In particular, $\mathrm{Ag}$ atoms tend to segregate at the surface of $\mathrm{Co}, \mathrm{Cu}$ and $\mathrm{Ni}$, to form thermodynamically stable phase-segregated structures. ${ }^{21-23}$ Nanocatalysts with phase segregated structures such as near-surface alloys, ${ }^{24}$ core-shells, ${ }^{25}$ Janus $^{-26}$ and hetero-structures,${ }^{27}$ demonstrate improved kinetics mainly due to electronic effects induced from the segregated phases. Electronic effects can be categorized into two major types: ${ }^{12,28}$ (i) the ligand effect originates from the atomic vicinity of two different metal atoms. This leads to a charge transfer between the adjacent atoms and results in the modification of their electronic structures at interfaces. In this way, surface chemical properties can be altered, for instance, $\mathrm{O}-\mathrm{O}$ breaking is facilitated..$^{24,28}$ (ii) The strain effect, compressive or tensile, is caused by a lattice mismatch between constituents. Upon a compressive strain, the d-orbitals' overlapping index increases. It results in the broadening of the catalysts' d-bands and, consequently, in the lowering of its average energy. Thereafter, the adsorption energies of oxygenated adsorbates are expected to decrease. ${ }^{29}$ Generally, ligand effects together with strain effects can synergistically alter the ORR activity of catalysts. Both effects usually co-exist and work as cumulative electronic effects. ${ }^{30}$ Deconvolution of these two effects is feasible using theoretical modeling. However, it is a rather challenging problem for experimentalists.

In addition to the enhanced activity, the stability of the catalyst under operating conditions is equally important. Recently, Back et $a l^{31}$ used density functional theory calculations to predict the stability and activity of a series of the noble-metal supported transition metal (oxy-hydro) oxide nanocatalysts. It was shown that the $\mathrm{NiOOH} \mid \mathrm{Ag}$ composite is one of the most promising candidates as alkaline ORR catalysts due to both enhanced activity and stability. Given these facts, Ag-Ni nanocomposites with well-defined structures could be promising candidates as catalysts for oxygen reduction in alkaline media.

As a facile technique for producing nanomaterials, $\gamma$-radiation induced synthesis has been proved to have some advantages over other methods, such as room temperature processing, minimal use of hazardous chemicals and precise control of the amount of reactive species. ${ }^{32,33}$ In the current study, core-shell Ag@NiO and heterostructured Ag/Ni nanocatalysts for the ORR were produced by using the above-mentioned $\gamma$-radiation induced synthesis method. Essential structural, chemical, and electrochemical characterization studies of the synthesized materials are performed to emphasize the effect of compositional and structural modulation on the activity of the nanocatalysts.

\section{Results and discussion}

\section{The general concept of $\boldsymbol{\gamma}$-radiation induced synthesis of nanoparticles}

The synthesis of materials by $\gamma$-radiation induced methods involves redox reactions of metal precursor salts with the products of water radiolysis. Upon absorbing ionizing radiation, water molecules undergo decomposition to form free radicals and active molecular species. The main radical products formed as a result of water radiolysis are hydroxyl radicals, $\mathrm{OH}^{\circ}$, and solvated electrons, $\mathrm{e}_{\mathrm{aq}}{ }^{-}$. In neutral water, those radicals are formed in equal amounts of $0.28 \mu \mathrm{mol} \mathrm{J}^{-1}$ and readily react with each other. ${ }^{34,35}$ The hydroxyl radicals are strong oxidants, while the solvated electrons are strong reductants (Table S1 $\dagger$ ). Thus, in order to tune the redox conditions of the solution to either reductive or oxidative, the undesired radical needs to be scavenged. To produce metallic nanomaterials, reductive conditions are created by adding, for example, propan-2-ol (IPA) as an $\mathrm{OH}^{*}$ scavenger. The reaction between IPA and $\mathrm{OH}^{*}$ results in the formation of reductive 2-hydroxyl-2propyl radicals, whose standard potential $v s$. the SHE is $-1.8 \mathrm{~V}^{36}$

$$
\mathrm{HO}^{\bullet}+\left(\mathrm{CH}_{3}\right)_{2} \mathrm{CHOH} \rightarrow \mathrm{H}_{2} \mathrm{O}+\left(\mathrm{CH}_{3}\right)_{2} \mathrm{COH}^{\bullet}
$$

These radicals and solvated electrons are the main agents responsible for metal atom formation from monovalent metal ions. $^{37}$

$$
\mathrm{Me}^{+}+\mathrm{e}_{\mathrm{aq}}{ }^{-} /\left(\mathrm{CH}_{3}\right)_{2} \mathrm{COH}^{\cdot} \rightarrow \mathrm{Me}^{0}
$$

For divalent ions the reduction may occur in the following sequence:

$$
\mathrm{Me}^{2+} \rightarrow \mathrm{Me}^{+} \rightarrow \mathrm{Me}^{0}
$$

Considering the oxidation state of $\mathrm{Ag}$ and $\mathrm{Ni}$ in the precursor solutions, the reduction of $\mathrm{Ag}^{+}$ions and $\mathrm{Ag}$ atom formation occur via reaction (2), while the reduction of $\mathrm{Ni}^{2+}$ to $\mathrm{Ni}^{0}$ may follow the route shown in reaction (3). The details of the $\gamma$-radiation induced synthesis of metallic $\mathrm{Ni}$ are given elsewhere. ${ }^{38}$ Since the binding energy between the metal atoms is stronger than that between the atom and solvent, the metal atoms tend to form dimers and subsequently clusters. The metal ions in the solution can also adsorb to the clusters and be reduced on the cluster surface. ${ }^{39}$ The size of the metal clusters can be controlled by adding polymers and surfactants. ${ }^{40}$ The final size of the clusters or nanoparticles is dependent on the initial polymer/ion ratio and, thus, polymer concentration in solutions.

\section{Fabrication of bimetallic Ag-Ni nanoparticles}

The synthesis procedures of the $\mathrm{Ag} @ \mathrm{NiO}$ and $\mathrm{Ag} / \mathrm{Ni}$ nanoparticles are illustrated in Fig. 1a. Core-shell Ag@NiO nanoparticles were synthesized by the co-reduction method where an aqueous solution containing both $\mathrm{Ag}$ and Ni salts was subjected to $\gamma$-radiation. The types of $\mathrm{Ag}$ and $\mathrm{Ni}$ species and the interaction between them under the synthesis conditions are 

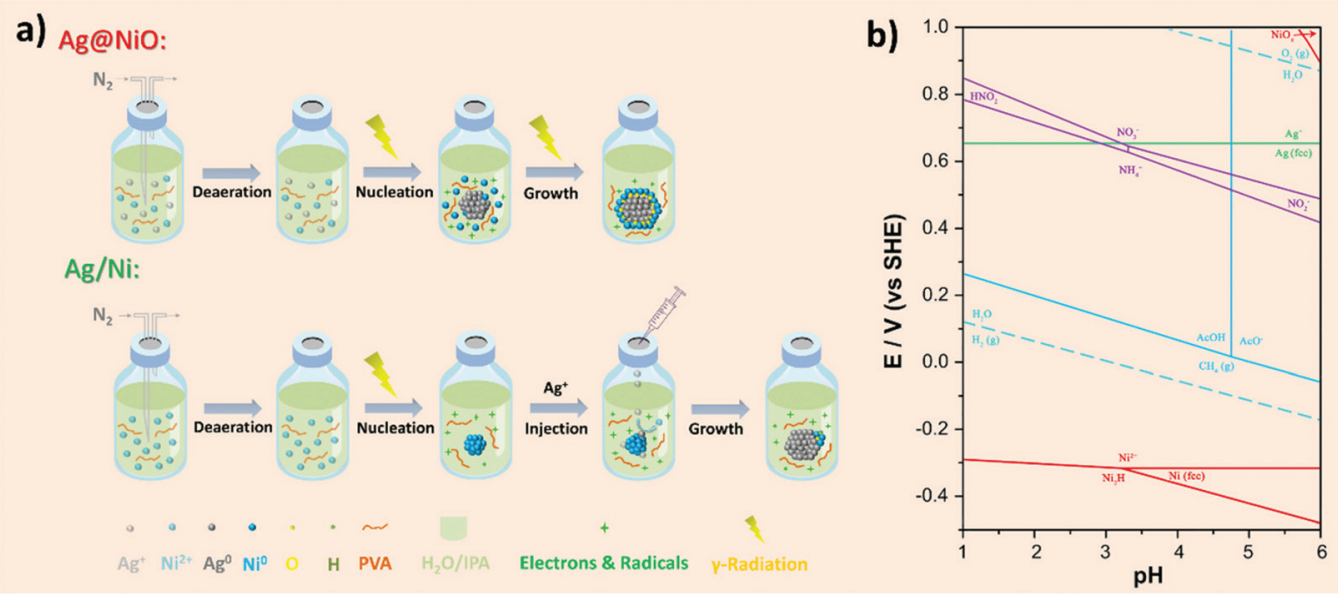

Fig. 1 (a) Synthesis procedure and formation process of $\mathrm{Ag} @ \mathrm{NiO}$ and $\mathrm{Ag} / \mathrm{Ni}$ nanoparticles. (b) The potential-pH diagram calculated for the $\mathrm{Ni}-\mathrm{Ag}-$ $\mathrm{NO}_{3}{ }^{-}-\mathrm{AcO}^{-}-\mathrm{H}_{2} \mathrm{O}$ system containing $5 \mathrm{mM}$ of $\mathrm{Ni}^{2+}$ and $\mathrm{Ag}^{+}$ions at $T=298.15 \mathrm{~K}$ and an atmospheric pressure of 1 bar.

predicted by using the calculated potential-pH diagram for the $\mathrm{Ni}-\mathrm{Ag}-\mathrm{NO}_{3}{ }^{-}-\mathrm{AcO}^{-}-\mathrm{H}_{2} \mathrm{O}$ system (Fig. 1b). The calculation details and parameters are presented in the ESI Chapter $3 . \dagger$ The chosen $\mathrm{pH}$ range in the diagram covers the experimental $\mathrm{pH}$ values, between 5.5 and 3 , measured before and after irradiation, respectively. As seen in the diagram, no hydrolysis of the metal cations occurs in the chosen $\mathrm{pH}$ range. No bimetallic Ag-Ni particles or mixed oxides are formed due to the homogeneous reactions in solutions, indicating that the interactions between the $\mathrm{Ag}$ and $\mathrm{Ni}$ species occur heterogeneously via the surface reactions.

The redox potential values for $\mathrm{Ag}$ and $\mathrm{Ni}$ calculated using actual experimental conditions correspond to 0.67 and -0.29 $\mathrm{V}$, respectively, which are close to the theoretical values (see Table $\mathrm{S} 1 \dagger$ ), indicating the affinity of the ions for the electrons and the species' tendency to be reduced is much higher in $\mathrm{Ag}$ as compared to that in Ni. Therefore, there will be a thermodynamic driving force to a selective reduction of $\mathrm{Ag}$ ions first, and the reduction of $\mathrm{Ni}$ will take place only when the system is depleted by the $\mathrm{Ag}^{+}$ions. ${ }^{41}$ Hence, the reduction of $\mathrm{Ni}^{2+}$ in solution and the homogeneous nucleation of the $\mathrm{Ni}$ cluster occur to a lesser extent. The nucleation of the Ag particles takes place according to the following reactions: ${ }^{39}$

$$
\begin{gathered}
\mathrm{Ag}^{0}+\mathrm{Ag}^{0} \rightarrow \mathrm{Ag}_{2} \\
\mathrm{Ag}^{0}+\mathrm{Ag}^{+} \rightarrow \mathrm{Ag}_{2}^{+}
\end{gathered}
$$

The dimers formed in reaction (4) later merge into larger clusters. The unreacted remaining Ag ions adsorb on the cluster surface (reaction (5)) and are reduced provided that the reducing agents are continuously supplied into the solution. Moreover, the reduced $\mathrm{Ag}$ particles act as seeds over which the Ni-rich phase nucleates and grows. The resulting particles will have a core with the noble metal (Ag) and a shell layer with the less noble metal (Ni). It agrees with the mechanism of bimetallic nanoparticle formation in solutions exposed to $\gamma$-irradiation proposed by Belloni et al. ${ }^{39,42}$ which implies that at a low dose rate an electron transfers from the less noble metal to the more noble one and, thereby, core-shell structures form. The strong oxidative ability of $\mathrm{Ag}^{+}$leads to the oxidation of metallic $\mathrm{Ni}$ in the shell and Ni oxide formation, which is confirmed by X-ray photoelectron spectroscopy (XPS) studies. The reaction between $\mathrm{Ni}$ and $\mathrm{Ag}$ can be described as reaction (6)

$$
2 \mathrm{Ag}^{+}+\mathrm{Ni}^{0} \rightarrow\left(\mathrm{Ag}_{2} \mathrm{Ni}\right)^{2+} \rightarrow 2 \mathrm{Ag}^{0}+\mathrm{Ni}^{2+}
$$

The formation of Ni oxide can occur due to the reaction of the Ni species with molecular oxygen, and the latter is formed as a result of the decomposition of $\mathrm{H}_{2} \mathrm{O}_{2}$ (one of the products of water radiolysis) on the solid surface.

Heterostructured Ag/Ni have been synthesized by a successive reduction where the $\mathrm{Ni}$ nanoparticles were obtained first by $\gamma$-radiation induced reduction from the corresponding precursor solution. The details about the $\gamma$-radiation induce synthesis of Ni nanoparticles performed under similar conditions to those used in the current study are given in our previous work. ${ }^{38}$ Thereafter the $\mathrm{AgNO}_{3}$ solution was added, and no further irradiation has been performed. Thus, the Ni-containing clusters can act as seeds for the heterogeneous nucleation and further growth of the Ag nanoparticles. The charge transfer between $\mathrm{Ag}$ and $\mathrm{Ni}$, reaction (6) that results in the oxidation of $\mathrm{Ni}$ surface layers, leads to the formation of $\mathrm{Ni}$ (oxy-hydro) oxide clusters.

\section{Structural and compositional investigation of the $\mathrm{Ag}-\mathrm{Ni}$ nanocatalysts}

To achieve the aim of the current study, the following samples were produced and analysed: monometallic nanoparticles (Ag, $\mathrm{Ni}$ and bimetallic Ag-Ni nanocatalysts: core-shell Ag@NiO, and heterostructured $\mathrm{Ag} / \mathrm{Ni}$. The morphology and structure of the obtained nanomaterials are investigated using transmission electron microscopy (TEM) and X-ray diffraction (XRD), respectively, and the surface atomic composition is obtained by XPS. Detailed analyses and descriptions of the monometallic Ag, Ni nanoparticles are shown in the ESI.† 
Structure and morphology revealed with TEM. Core-shell $\mathrm{Ag} @ \mathrm{NiO}$ nanoparticles were obtained in the form of a black precipitate by irradiating a mixture containing $\mathrm{Ag}$ and Ni salts in an equal amount. The morphology of the precipitate was studied using TEM, and the results are presented in Fig. 2. The core-shell structure is confirmed by energy dispersive $\mathrm{X}$-ray spectrometry (EDS) mapping shown in Fig. 2(e-g), where both $\mathrm{Ag}$ and $\mathrm{Ni}$ are present, but there is much more $\mathrm{Ni}$ in the outer layer. The Ag@NiO nanoparticles consist of large (162 $\mathrm{nm}$ on average) faceted particles (core) surrounded by a thin layer/shell (of about $2 \mathrm{~nm}$ thick), as demonstrated in Fig. 2(a and b). The composition of the core corresponds to metallic Ag that has a fcc structure as determined from the selected area electron diffraction (SAED) pattern (Fig. 2c). The presence of fcc $\mathrm{Ag}$ is confirmed by XRD studies (Fig. 4a). The interatomic distances determined from the high-resolution image and fast Fourier transform (FFT) pattern, shown in Fig. 2b, correspond to the (111) and (200) planes in metallic $\mathrm{Ag}$. The lattice parameter of the $\mathrm{Ag}$ core calculated using the XRD pattern is $4105 \pm 0.007 \AA$, (all lattice parameters of $\mathrm{Ag}$ obtained from XRD and SAED are presented in Table S2 $\dagger$ ). The shell represents an adjacent $\mathrm{Ni}$ atom containing an amorphous layer/shell of about $2 \mathrm{~nm}$ at the surface of the $\mathrm{Ag}$ core. As demonstrated in Fig. 2b, the interfaces between the crystalline $\mathrm{Ag}$ core and amorphous Ni-based shell are continuous and do not contain any pores or voids.

Heterostructured $\mathrm{Ag} / \mathrm{Ni}$ nanoparticles are composed of single crystal Ag nanoparticles (the average size of $45 \mathrm{~nm}$ ) and adjacent Ni-containing polycrystalline clusters, as seen in
Fig. 3. These clusters, whose diameters are ranging from 10 to $20 \mathrm{~nm}$, consist of primary particles (with the size of $3 \mathrm{~nm}$ ). The SAED pattern shown in Fig. 3c corresponds solely to the diffraction pattern from metallic fcc Ag. No clear signal from the Ni compounds is registered by the electron diffraction technique. However, the interatomic distances of the Ni-containing crystals, determined from the HRTEM image (Fig. 3b), are $d=0.231 \mathrm{~nm}$ that may correspond to either the (101) planes in $\mathrm{Ni}(\mathrm{OH})_{2}$, or the (102) planes in $\mathrm{Ni}_{2} \mathrm{O}_{3} / \mathrm{NiOOH}$, while $d=0.197 \mathrm{~nm}$ corresponds to $\mathrm{Ni}(111) .{ }^{43,44}$ Thus, the epitaxial relationship between $\mathrm{Ag}$ and $\mathrm{Ni}$ (oxy-hydro) oxide can be shown in the following: $\mathrm{Ag}[100] / / \mathrm{Ni}(\mathrm{OH})_{2}[101]$ or/and Ag $[100] / / \mathrm{Ni}_{2} \mathrm{O}_{3}(\mathrm{NiOOH})$ [102]. The calculated lattice mismatch is about $11 \%$, where $\mathrm{Ni}$ (oxy-hydro) oxide undergoes a compressive strain at the surface of Ag. Except for the conventional lattice plane, a Moiré pattern is observed (the area is labeled with a rectangle in Fig. 3b). The Moiré pattern is an optical phenomenon that indicates the coexistence of two sub-lattices that are either disoriented with respect to each other or have slightly different lattice constants. ${ }^{45}$ Thus, the appearance of the Moiré pattern can be ascribed to the interferences from two randomly oriented $\mathrm{Ag}$ crystals and/or from the heterostructure formed at the interfaces between the $\mathrm{Ag}$ nanoparticles and the Ni-based nanoclusters.

Phase composition of the bimetallic samples studied with XRD. The XRD patterns of the Ag@NiO, Ag/Ni and reference $\mathrm{Ag}$ samples are presented in Fig. 4. The high-intensity diffraction peaks corresponding to fcc $\mathrm{Ag}^{46}$ are visible for all
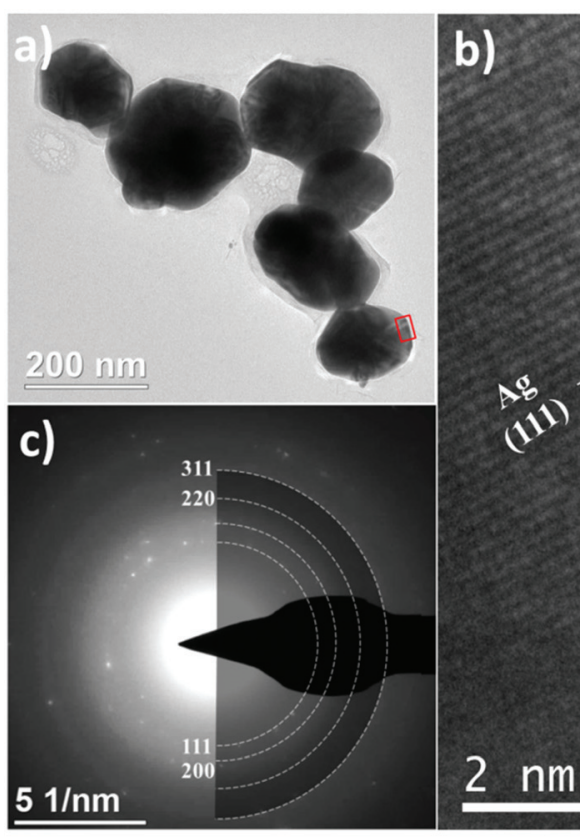

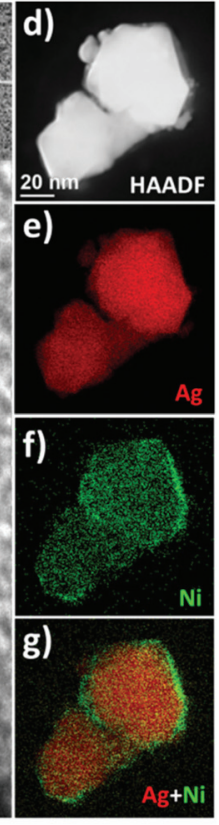

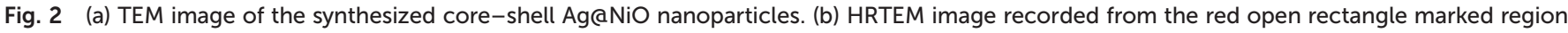

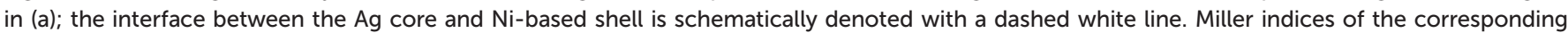

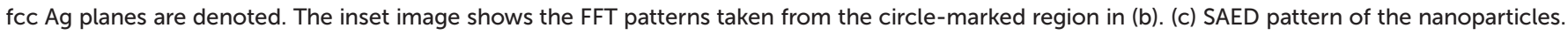

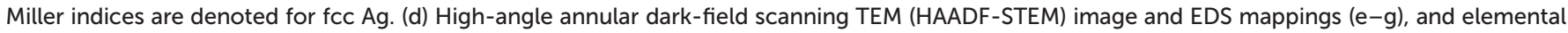
$\mathrm{Ag}$ and $\mathrm{Ni}$ are labeled with red and green, respectively. 

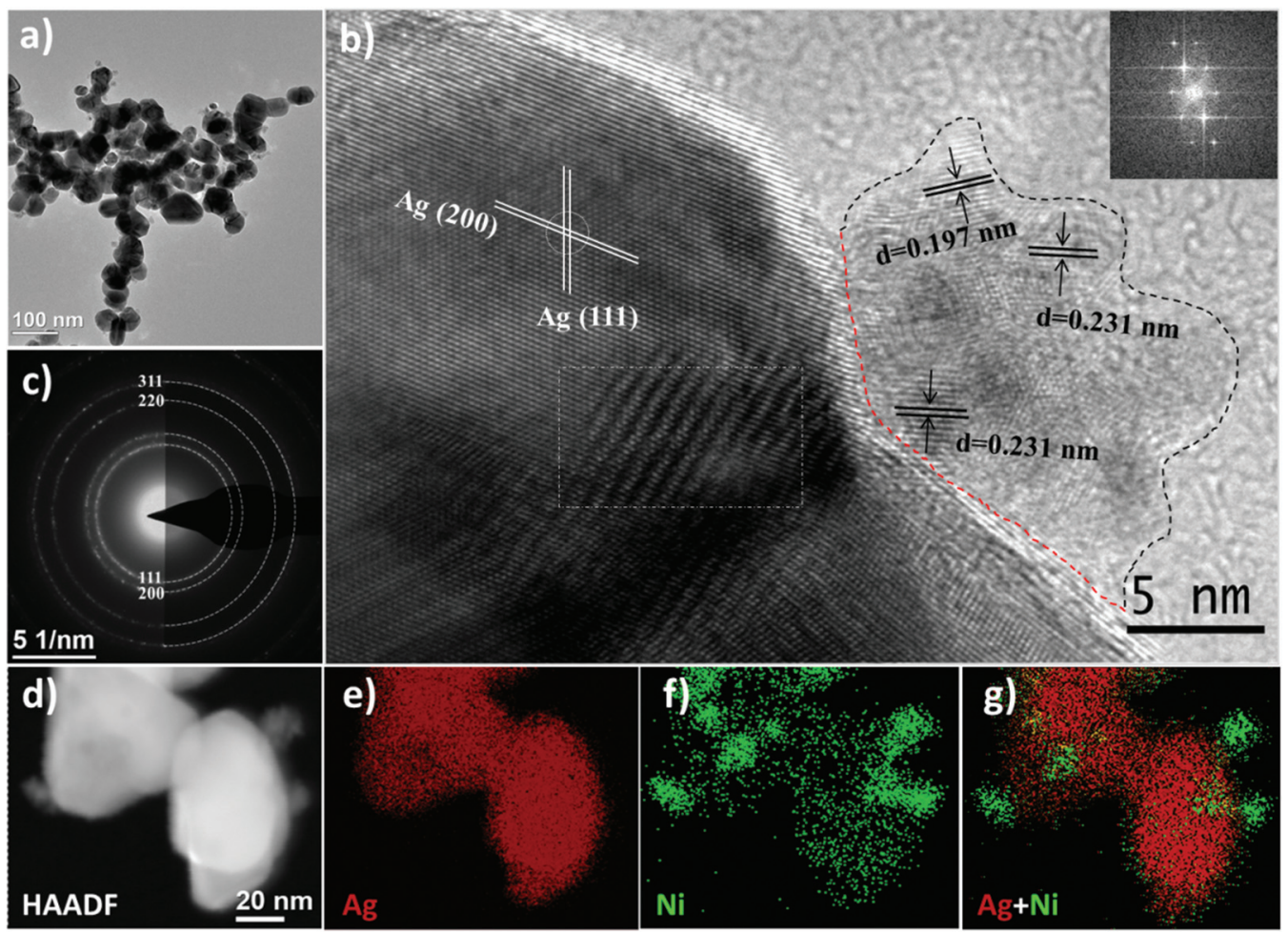

Fig. 3 Ag-Ni heterostructures: (a) TEM image; (b) HRTEM image; the inset shows the FFT patterns taken from the circle-marked region in (b). The crystallographic planes and corresponding Miller indices are denoted, and the interface between the Ag nanoparticles and Ni compound is schematically denoted with the dashed red line; (c) SAED pattern. The reflection indices corresponding to fcc Ag are labeled (d) HAADF-STEM image and EDS mappings $(\mathrm{e}-\mathrm{g})$, and elemental $\mathrm{Ag}$ and $\mathrm{Ni}$ are denoted with red and green, respectively.
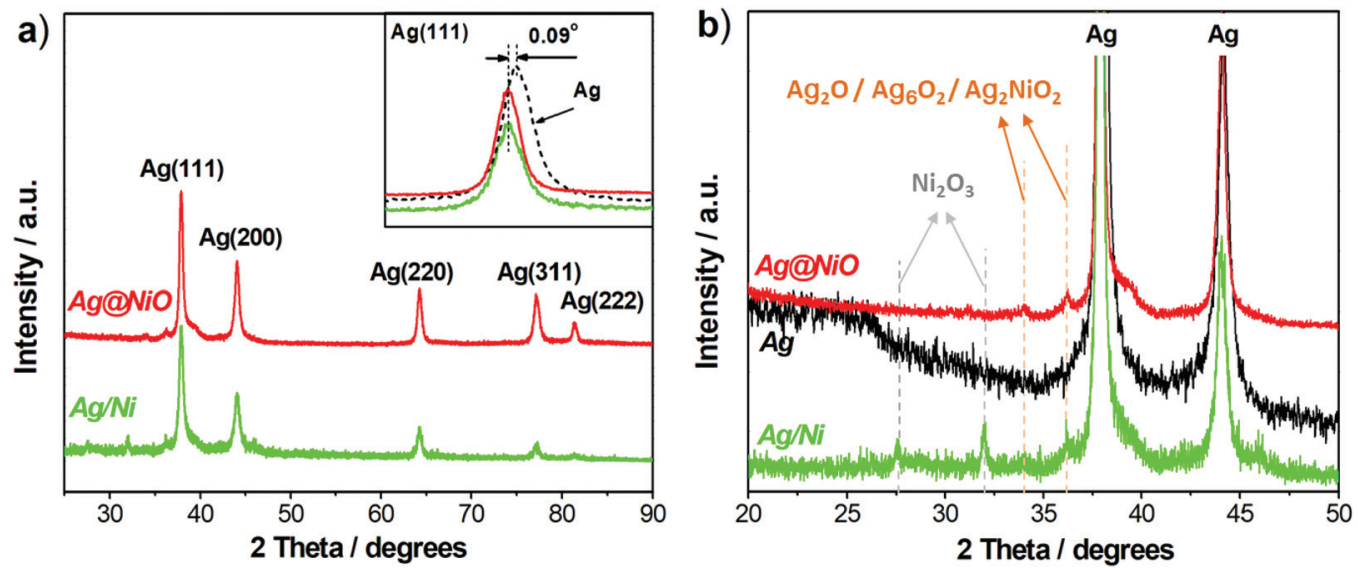

Fig. 4 (a) XRD patterns of Ag@NiO, core-shells and Ag/Ni heterostructures. Miller indices of the corresponding Ag peaks are denoted. The details of the Ag (111) peaks are shown in the inset. The black dashed curve corresponds to the XRD pattern recorded for the Ag nanoparticles. (b) The magnified $\left(2 \theta=20-50^{\circ}\right)$ part of the XRD patterns containing low intensity peaks, recorded from the Ag@NiO, Ag/Ni and Ag nanoparticles. Possible compounds with low density peaks are labeled in $\mathrm{b}$.

samples. Meanwhile, several low intensity peaks in the $2 \theta$ range from 20 to $37^{\circ}$ have been observed only on the diffractograms recorded from the bimetallic samples but not from the reference ones. Although, the main crystalline phase formed during the synthesis is metallic $\mathrm{Ag}$, the low-intensity XRD peaks recorded for both $\mathrm{Ag} @ \mathrm{NiO}$ and $\mathrm{Ag} / \mathrm{Ni}$ samples indicate the presence of other Ag- and/or Ni-based compounds. Thus, the XRD peaks at $2 \theta \approx 34^{\circ}$ and $36.2^{\circ}$, shown in Fig. $4 \mathrm{~b}$, can be ascribed to $\mathrm{Ag}$ oxides $\mathrm{Ag}_{2} \mathrm{O}_{6}{ }^{47}$ and $\mathrm{Ag}_{2} \mathrm{O}\left(\mathrm{Ag}_{2} \mathrm{~F} \text { type }\right)^{48}$ and/or to a mixed oxide $\mathrm{Ag}_{2} \mathrm{NiO}_{2} \cdot{ }^{49}$ While in the $\mathrm{Ag} / \mathrm{Ni}$ sample, the lowintensity peaks at $2 \theta=27.6^{\circ}$ and $31.9^{\circ}$ can be attributed to rhombohedral $\mathrm{Ni}_{2} \mathrm{O}_{3} \cdot{ }^{50}$ Possible compounds detected with 
XRD are listed in Table S3.† Note that the diffraction peaks neither from metallic Ni nor from NiO are observed. This may be due to the fact that the main XRD peak positions for fcc $\mathrm{Ni}^{51}$ and fcc $\mathrm{NiO}^{52}$ are overlapping with those for $\mathrm{Ag}$. Thus, the diffraction peak from $\mathrm{Ni}(111)$ appears at $2 \theta=44.5^{\circ}$ almost overlapping with that from $\mathrm{Ag}(200)\left(2 \theta=44.3^{\circ}\right)$. As confirmed by TEM, the Ni-based compounds in our samples have much poorer crystallinity than the $\mathrm{Ag}$ : Ni-based compounds present in the samples either as thin amorphous layers (Ag@NiO) or as clusters that consist of primary particles with $2-3 \mathrm{~nm}$ in diameter. Therefore, X-ray diffraction is less sensitive to the Nibased compounds in our samples. In addition, as seen in the insert in Fig. 4a, the positions of the $\mathrm{Ag}(111)$ peaks recorded from $\mathrm{Ag} @ \mathrm{NiO}$ and $\mathrm{Ag} / \mathrm{Ni}$ are shifted by $0.09^{\circ}$ towards lower $2 \theta$ with regard to that recorded from the metallic $\mathrm{Ag}$ sample (used as a reference). This indicates the presence of small crystal lattice distortions in the Ag-Ni samples. These distortions correspond to the $\mathrm{Ag}$ crystal lattice expansion of $0.65 \%$ in $\mathrm{Ag} @ \mathrm{NiO}$ and $\mathrm{Ag} / \mathrm{Ni}$ as compared to the reference $\mathrm{Ag}$ sample. Thus, the X-ray diffraction study reveals that both bimetallic Ag-Ni nanoparticles consist of crystalline $\mathrm{Ag}$ and phases with low crystallinity which contain Ag- and Ni-based oxides.

Surface chemical composition of $\mathrm{Ag}$ and bimetallic $\mathrm{Ag}-\mathrm{Ni}$ validated with XPS analysis. To further verify the composition and structure of the studied samples, XPS analysis was performed, and the resulting spectra are shown in Fig. 5. The binding energies (BE) of the $\mathrm{O} 1 \mathrm{~s}, \mathrm{Ag} 3 \mathrm{~d}$ and $\mathrm{Ni} 2 \mathrm{p}$ core levels and the atomic ratio of $\mathrm{Ag}$ and $\mathrm{Ni}$ in the samples measured with XPS are given in Table S4. $\dagger$ The structural and compositional studies of free-standing Ni nanoparticles, produced by $\gamma$-radiation induced synthesis, were shown in our previous work. ${ }^{38}$ Detailed XPS analysis of the Ag nano- particles is shown in the ESI (Table $\mathrm{S} 4 \dagger$ and the text below it).

For core-shell Ag@NiO sample, analysis of the XPS spectra reveals the $\mathrm{Ag} 3 \mathrm{~d}_{5 / 2}$ BE peaks located at $368.6 \mathrm{eV}$ and $368.2 \mathrm{eV}$. Note that the lower value is close to the $\mathrm{BE}$ of the $\mathrm{Ag}-\mathrm{Ag}$ bonds in bulk. ${ }^{53}$ Since the diameter of the Ag@NiO core-shell structures is much larger than that of the Ag nanoparticles, the size effect on the electronic structure can be neglected. Hence, the $\mathrm{BE}$ of $368.2 \mathrm{eV}$ is attributed to metallic Ag. The higher energy peak may belong to $\mathrm{Ag}$ in the bimetallic compounds. As reported in the literature, the binding energies for $\mathrm{Ag} 3 \mathrm{~d}$ in the $\mathrm{Ag}-\mathrm{Ni}(\mathrm{OH})_{2}$ composites may shift from $0.2 \mathrm{eV}$ to $0.55 \mathrm{eV}$ towards higher energies with respect to those in pure Ag. ${ }^{54,55}$ The Ni $2 p_{3 / 2}$ photoelectron lines exhibit a shoulder towards high BEs, which is characteristic of NiO. ${ }^{56}$ The asymmetry of the peak originates from the partial overlapping of the multiplet splitting of $\mathrm{NiO}$ and its $2 \mathrm{p}_{3 / 2}$ peaks found at $854.7 \mathrm{eV}$ and $856.5 \mathrm{eV}$, together with its $2 \mathrm{p}_{1 / 2}$ peaks at $872.4 \mathrm{eV}$ and $874.2 \mathrm{eV}$ are in good agreement with the literature. ${ }^{57}$

The deconvoluted spectrum of $\mathrm{Ni} 2 \mathrm{p}$ for the $\mathrm{Ag} / \mathrm{Ni}$ sample shows several photoelectron peaks, both primary and secondary. There are three primary peaks resulting from the ejection of a core level electron located at $852.4 \mathrm{eV}, 854.3 \mathrm{eV}$, and 856.5 $\mathrm{eV}$. The first peak is attributed to the $2 \mathrm{p}_{3 / 2}$ spectral line from metallic $\mathrm{Ni},{ }^{58}$ while the second and third peaks may belong to the $\mathrm{Ni}$ (oxy-hydro) oxides $\left(\mathrm{Ni}_{2} \mathrm{O}_{3}\right.$ and/or NiOOH) ${ }^{59,60}$ Likewise, the primary peaks at $869.7 \mathrm{eV}, 871.8 \mathrm{eV}$, and $874 \mathrm{eV}$ are attributed to the $2 \mathrm{p}_{1 / 2}$ peaks of the same compounds. Higher energy singlet broad peaks at $859.4 \mathrm{eV}, 863.1 \mathrm{eV}, 877.6 \mathrm{eV}$ and 881.8 $\mathrm{eV}$ are reported to correspond to a plasmon-loss peak from metallic $\mathrm{Ni}$ and shake-up satellite peaks emerge from the $\mathrm{Ni}-$ $\mathrm{O}-\mathrm{H}$ compounds. ${ }^{60}$ Integration of the primary peaks reveals that $90 \%$ of $\mathrm{Ni}$ found within the probing depth, of about
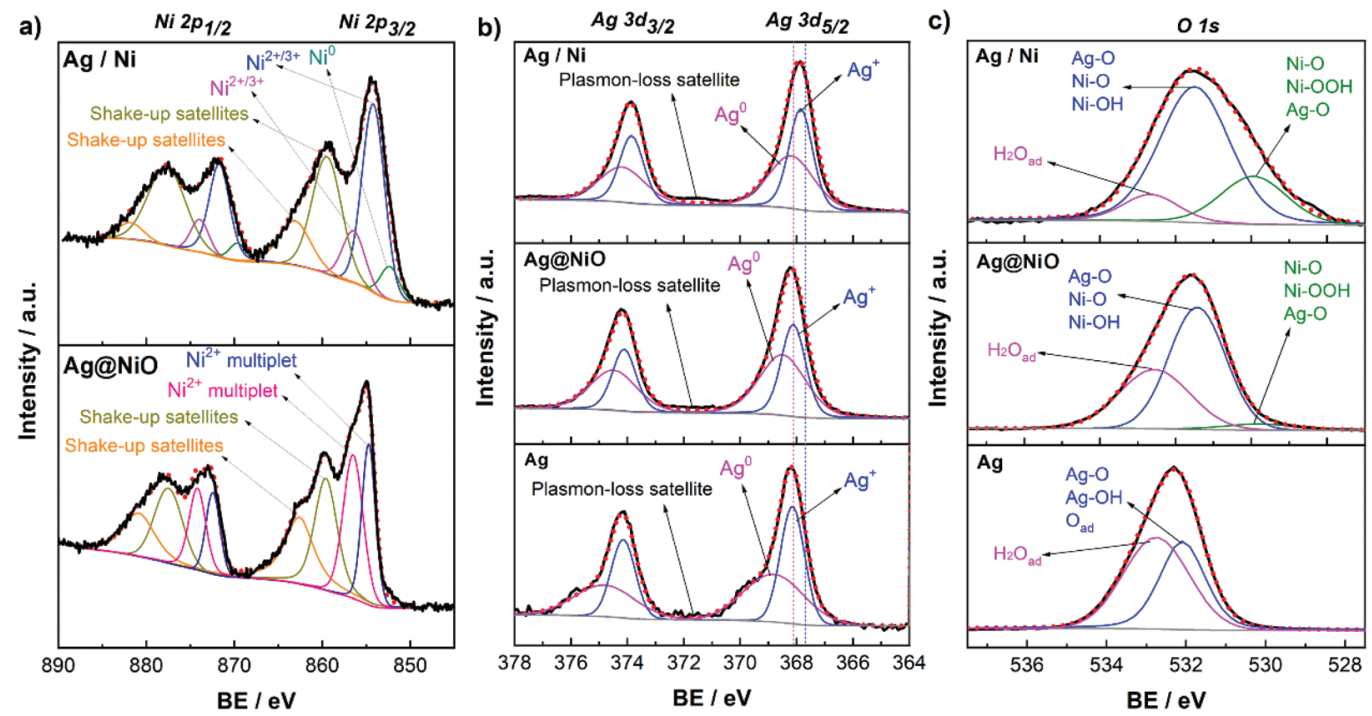

Fig. 5 XPS spectra of the Ag@NiO and Ag/Ni samples for Ni 2p (a), Ag, Ag@NiO, and Ag/Ni NPs for Ag 3d (b) and O 1s (c). The black solid lines represent the original spectra and red dot lines represent the fits to the data. The dash lines in (b) at $368.1 \mathrm{eV}$ and $367.7 \mathrm{eV}$ correspond to the BEs of bulk $\mathrm{Ag}^{0}$ and $\mathrm{Ag}^{+}$, respectively. 
$6 \mathrm{~nm}$, corresponds to $\mathrm{Ni}^{2+} / \mathrm{Ni}^{3+}$ and the remaining $10 \%$ to metallic Ni. It is known that $\mathrm{Ni}$ is readily oxidized by water and, consequently, the $\mathrm{Ni}^{2+} / \mathrm{Ni}^{3+}$ oxide/hydroxide layers cover the surface of the metallic Ni particles. ${ }^{38}$ Note that other $\mathrm{Ni}$ compounds such as $\mathrm{Ni}_{2} \mathrm{O}_{3}{ }^{61}$ or mixed oxides Ag-Ni-O, ${ }^{49,62}$ whose $\mathrm{Ni} 2 \mathrm{p}$ BEs are within the same range as those for $\mathrm{Ni}-\mathrm{O}$ and $\mathrm{Ni}-\mathrm{O}-\mathrm{H}$, may also be present in both $\mathrm{Ag@NiO}$ and $\mathrm{Ag} / \mathrm{Ni}$ nanomaterials. The peaks at BEs of 367.9 and $368.2 \mathrm{eV}$ are attributed to $\mathrm{Ag} 3 \mathrm{~d}_{5 / 2}$ of $\mathrm{Ag}_{2} \mathrm{O}$ and metallic $\mathrm{Ag}$, respectively. ${ }^{53}$ The plasmon-loss satellites at 371.5 and $377.4 \mathrm{eV}$ confirmed the existence of metallic $\mathrm{Ag}$ as described above. The presence of the $\mathrm{Ag}_{2} \mathrm{O}$ may be ascribed to the adjacent $\mathrm{Ni}$ (oxy-hydro) oxides $\left(\mathrm{Ni}(\mathrm{OH})_{2} / \mathrm{Ni}_{2} \mathrm{O}_{3} / \mathrm{NiOOH}\right)$ with strong electronic affinity which would promote the electron-depleted $\mathrm{Ag}$ to be oxidized. $^{63}$

\section{Electrochemical performance of the $\mathrm{Ag}-\mathrm{Ni}$ nanocatalysts}

Cyclic voltammetry (CV). CV measurements were conducted in $\mathrm{N}_{2}$ saturated $0.1 \mathrm{M} \mathrm{KOH}$ solution at a scan rate of $50 \mathrm{mV}$ $\mathrm{s}^{-1}$. After 20-50 activation cycles, stable CV curves were recorded (Fig. 6a). The CV curves of both bimetallic samples show distinct double oxidation peaks: the one that appears at $1.35 \mathrm{~V}$ corresponds to the formation of $\mathrm{Ag}_{2} \mathrm{O}$, and this peak coincides with the oxidation peak observed for the $\mathrm{Ag}$ sample ${ }^{64}$ the peak at $1.48 \mathrm{~V}$ can be attributed to the formation of $\mathrm{Ni}(\mathrm{III})(\mathrm{NiOOH}) .{ }^{65,66}$ It should be noted that the $\mathrm{CV}$ curve recorded for the Ni sample shows the same feature. This indicates that, in the bimetallic Ag-Ni samples, both $\mathrm{Ag}$ and $\mathrm{Ni}$ are involved in the electrochemical reactions. Thus, in the coreshell Ag@NiO sample, the Ag core is partially exposed to the electrolyte rather than being fully covered with the NiO shell layers. The electrochemical surface areas (ECSAs) of the Ag, $\mathrm{Ag} @ \mathrm{NiO}$ and $\mathrm{Ag} / \mathrm{Ni}$ samples determined from the $\mathrm{Pb}_{\text {upd }}$-stripping voltammogram are shown in Fig. 6b, where a pair of typical Pb-stripping peaks appears between 0.2 and $0.5 \mathrm{~V}$. The ESCA for Ag/Ni and Ag@NiO is found to be $41.90 \mathrm{~m}^{2} \mathrm{~g}^{-1}$ and
$30.38 \mathrm{~m}^{2} \mathrm{~g}^{-1}$, respectively. The ECSA of monometallic Ag is a bit larger $\left(43.6 \mathrm{~m}^{2} \mathrm{~g}^{-1}\right)$, which could be ascribed to the small particle sizes (a bimodal particle size distribution with $7.4 \mathrm{~nm}$ and $18.0 \mathrm{~nm}$ ) in the monometallic Ag sample (Table S5† shows the ECSA of Ni and detailed calculation parameters). Besides this, the five-fold twinned structure of the $\mathrm{Ag}$ nanoparticles may also contribute to their electrochemical activity due to the increased amount of active sites because of the additional edges appearing between the twins and induced lattice strain. $^{67}$

Oxygen reduction reaction. The electrocatalytic performance for the ORR of the obtained catalysts was investigated and the polarization curves are shown in Fig. 7a. The measurements were done at a scan rate of $10 \mathrm{mV} \mathrm{s}^{-1}$ and a rotation speed of $1600 \mathrm{rpm}$. The ORR onset potential, $E_{\text {onset }}$, and half-wave potential, $E_{1 / 2}$, derived from the polarization curves are presented in Fig. 7b. The data are summarized in Table 1. The $E_{\text {onset }}$ value of both bimetallic Ag-Ni samples (around $0.82 \mathrm{~V}$ ) is higher than that of monometallic $\mathrm{Ag}$ and $\mathrm{Ni}$, although it is lower than that of commercial Pt/C. This result can be confirmed with the onset oxidation potentials of Ag@NiO, and Ag/ $\mathrm{Ni}$ (shown in the insert in Fig. 6a). The onset oxidation potentials of bimetallic $\mathrm{Ag}-\mathrm{Ni}$ are lower than those of pure $\mathrm{Ag}$, thereby indicating that the surface of the bimetallic $\mathrm{Ag}-\mathrm{Ni}$ nanoparticles is oxidized more readily than that of $\mathrm{Ag}$. The increased $E_{\text {onset }}$ for $\mathrm{Ag} @ \mathrm{NiO}$ and $\mathrm{Ag} / \mathrm{Ni}$ could be attributed to the enhanced water-activation ability of the $\mathrm{Ni}$ compounds ( $\mathrm{NiO}$ and $\mathrm{Ni}$ (oxy-hydro) oxides in the $\mathrm{Ag} @ \mathrm{NiO}$ and $\mathrm{Ag} / \mathrm{Ni}$ samples, respectively). ${ }^{28,68}$ Similarly, the two bimetallic samples also show larger $E_{1 / 2}$ values than the monometallic materials. However, the difference is not as distinct as that in $E_{\text {onset }}$.

The ORR kinetics have been investigated by recording the polarization curves at various rotation speeds (Fig. S2(a-d) $\dagger$ ). Based on the polarization curves, the electron transfer number $(n)$ is then calculated at $0.5 \mathrm{~V}$ using the Koutecky-Levich $(\mathrm{K}-\mathrm{L})$
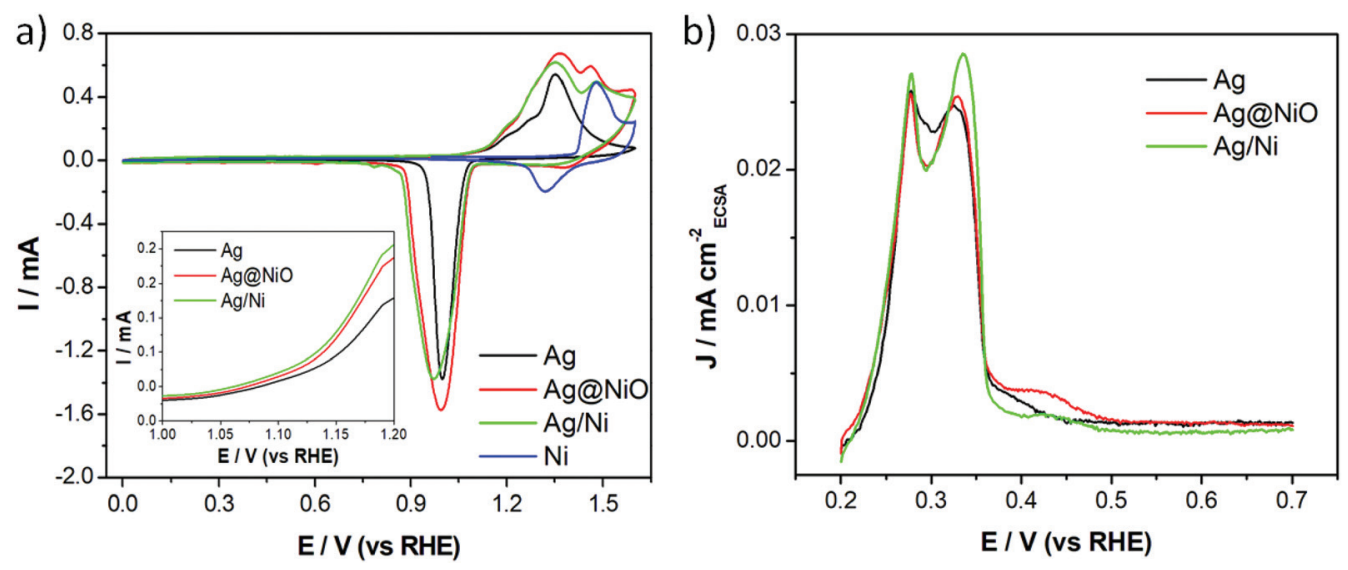

Fig. 6 (a) Cyclic voltammetry curves of $\mathrm{Ag}, \mathrm{Ag} @ \mathrm{NiO}, \mathrm{Ag}-\mathrm{Ni}$ and $\mathrm{Ni}$ recorded in $0.1 \mathrm{M} \mathrm{N}_{2}$ saturated $\mathrm{KOH}$ solution at a scan rate of $50 \mathrm{mV} \mathrm{s}{ }^{-1}$; the inset shows the magnified curves showing the onset oxidation potential of $\mathrm{Ag}$, $\mathrm{Ag} @ \mathrm{NiO}$, and $\mathrm{Ag} / \mathrm{Ni}$. (b) Stripping voltammogram of $\mathrm{Pb}$ upd on $\mathrm{Ag}$, $\mathrm{Ag} @ \mathrm{NiO}$, and $\mathrm{Ag}-\mathrm{Ni}$ in $\mathrm{N}_{2}$ saturated $0.1 \mathrm{M} \mathrm{KOH}+125 \mu \mathrm{M} \mathrm{Pb}\left(\mathrm{NO}_{3}\right)_{2}$ solution at a scan rate of $10 \mathrm{mV} \mathrm{s}^{-1}$, and the current was normalized with ECSA. 

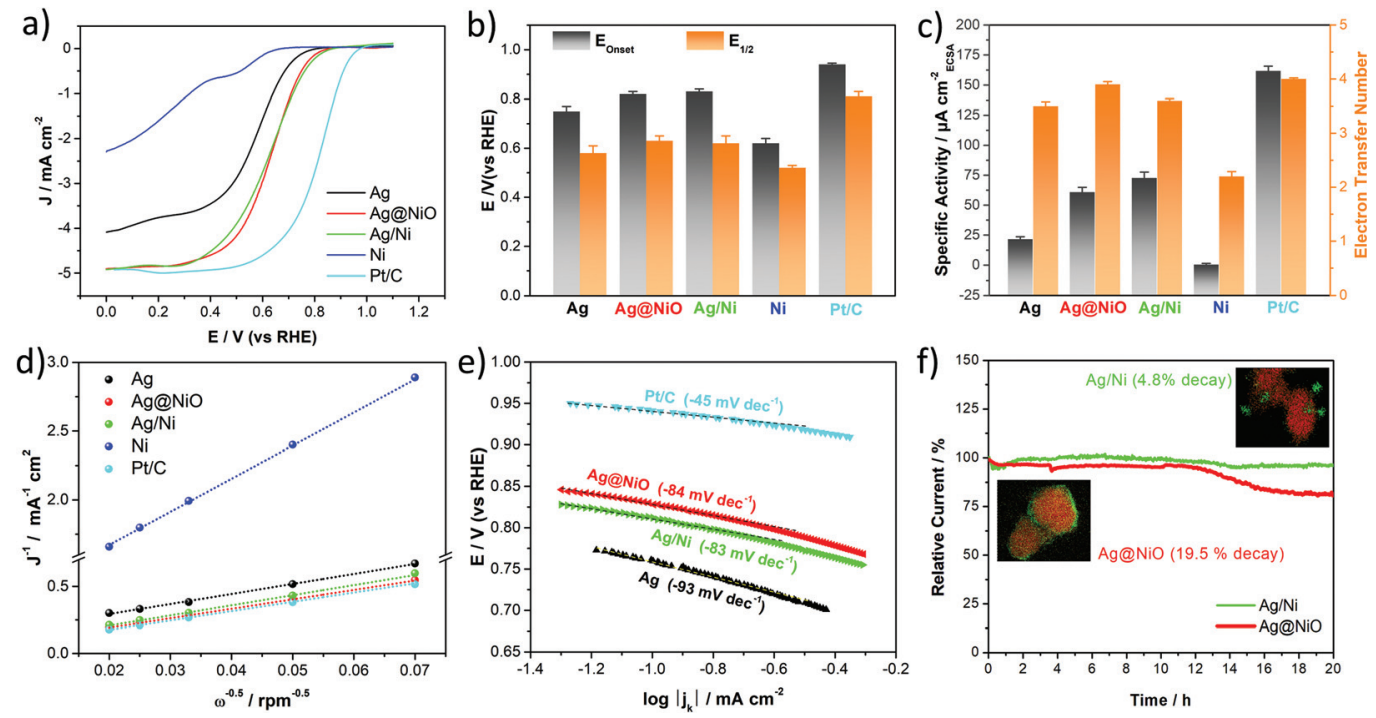

Fig. 7 Electrocatalytic performance of $\mathrm{Ag}, \mathrm{Ag}(\mathrm{NiO}, \mathrm{Ag} / \mathrm{Ni}, \mathrm{Ni}$, and commercial Pt/C (20 wt\%, ETEK) used as a reference. (a) ORR polarization curves obtained at a rotation speed of $1600 \mathrm{rpm}$ in $\mathrm{O}_{2}$-saturated $0.1 \mathrm{M} \mathrm{KOH}$. (b) Histograms of onset potentials $\left(E_{\text {onset }}\right)$ and half-wave potentials $\left(E_{1 / 2}\right)$, (c) histograms of specific activity (SA) and electron transfer numbers (calculated at $0.5 \mathrm{~V}$ ) for all studied samples; the standard deviations in (b) and (c) were obtained from three repeated electrochemical tests, (d) $\mathrm{K}-\mathrm{L}$ plots at $0.5 \mathrm{~V}$, and (e) Tafel plots derived from a; the absolute slope values are labeled. All the polarization curves were recorded at a scan rate of $10 \mathrm{mV} \mathrm{s}^{-1}$. (f) Chronoamperometric responses (the percentage of the current retained versus the operation time) of $\mathrm{Ag}\left(\mathrm{NiO}\right.$ and $\mathrm{Ag} / \mathrm{Ni}$ at $0.65 \mathrm{~V}$ in $\mathrm{O}_{2}$-saturated $0.1 \mathrm{M} \mathrm{KOH}$.

Table 1 Electrochemical parameters of the studied nanocatalysts and $\mathrm{Pt} / \mathrm{C}$, used as a reference. Electrochemical measurements on all the samples were repeated at least three times ${ }^{a}$

\begin{tabular}{llllll}
\hline Catalyst & $\begin{array}{l}\text { Onset potential } \\
E_{\text {onset }}(\mathrm{V})\end{array}$ & $\begin{array}{l}\text { Half-wave potential } \\
E_{1 / 2}(\mathrm{~V})\end{array}$ & $\begin{array}{l}\text { Diffusion limiting current } \\
\text { density } j_{\mathrm{d}}\left(\mathrm{mA} \mathrm{cm}^{-2}{ }_{\mathrm{GEO}}\right)\end{array}$ & $\begin{array}{l}\text { Specific activity SA @0.65 V } \\
\left(\mu \mathrm{A} \mathrm{cm}^{-2} \mathrm{ECSA}^{2}\right.\end{array}$ & $\begin{array}{l}\text { Electron transfer } \\
\text { number } n\end{array}$ \\
\hline $\mathrm{Ag}$ & 0.75 & 0.55 & 3.8 & 21.6 & 3.5 \\
$\mathrm{Ag} @ \mathrm{NiO}$ & 0.82 & 0.59 & 4.9 & 70.8 & 3.9 \\
$\mathrm{Ag} / \mathrm{Ni}$ & 0.83 & 0.60 & 4.9 & 0.4 & 3.6 \\
$\mathrm{Ni}$ & 0.62 & 0.52 & 0.7 & 161.7 (@0.9 V) & 2.2 \\
$\mathrm{Pt} / \mathrm{C}$ & 0.94 & 0.81 & 5.0 &
\end{tabular}

${ }^{a}$ The experimental uncertainty of $E_{\text {onset }}, E_{1 / 2}$ is $0.01 \mathrm{~V} ; j_{\mathrm{d}}$ and the SA are $0.1 \mathrm{~mA} \mathrm{~cm}^{-2}$ and $\mu \mathrm{A} \mathrm{cm}{ }^{-2}$, respectively; $n$ is 0.1 .

equation. ${ }^{69}$ The $\mathrm{K}-\mathrm{L}$ plots at $0.5 \mathrm{~V}$ for the studied samples, including commercial $\mathrm{Pt} / \mathrm{C}$ (20 wt\%, ETEK) used as a reference, are shown in Fig. 7 d. The calculation details and K-L plots at different potentials (inserts in Fig. S2(a-d)†) are shown in the ESI. $\dagger$ The calculated electron transfer number is presented as a histogram in Fig. $7 \mathrm{c}$ and listed in Table 1. As seen in the table, all Ag-based samples including Ag, Ag@NiO and $\mathrm{Ag} / \mathrm{Ni}$ possess an electron transfer number greater than 3.5, demonstrating a mainly four-electron transfer pathway. However, the $n$-values of the $\mathrm{Ag}$ and $\mathrm{Ag} / \mathrm{Ni}$ samples are slightly lower than those of $\mathrm{Ag} @ \mathrm{NiO}$ and $\mathrm{Pt} / \mathrm{C}$, indicating that some peroxide is formed on the $\mathrm{Ag}$ and $\mathrm{Ag} / \mathrm{Ni}$ catalysts. Thus, the ORR for these samples proceeds at least partially via the $2+2$ electron pathway. ${ }^{70}$ For commercial Pt/C, our previous study confirmed that the obtained electrochemical parameters were within the normal range for the Pt/C catalyst $\left(E_{\text {onset }}=0.94 \mathrm{~V}\right.$, $\left.E_{1 / 2}=0.82 \mathrm{~V}\right) .^{71}$ The diffusion limiting current density, $j_{\mathrm{d}}$, values (shown in Table 1) of bimetallic Ag@NiO and Ag/Ni are higher $\left(4.9 \mathrm{~mA} \mathrm{~cm}^{-2}\right)$ than those of the monometallic catalysts and pretty close to those of $\mathrm{Pt} / \mathrm{C}$.

The specific activity, SA, the current per unit catalyst surface area, is commonly used to reflect the intrinsic activity of the catalysts. ${ }^{72}$ To make a clear comparison, the SA for all prepared samples is calculated at $0.65 \mathrm{~V}$ instead of the commonly used potential $0.8 \mathrm{~V},{ }^{10,73}$ and the result is shown in Fig. 7c. The bimetallic Ag-Ni samples display an enhanced SA with around 3 times improvement relative to monometallic Ag, which is much higher than that of Ni prepared under the same conditions. The SA for Pt/C is calculated to be $161.7 \mu \mathrm{A}$ $\mathrm{cm}^{-2}$ Pt at $0.9 \mathrm{~V}$. The catalytic performance of the samples presented in the current study is not high enough as compared to that of $\mathrm{Pt} / \mathrm{C}$, however, the calculated activity is quite consistent with the previous results for the Ag-based catalysts. ${ }^{6,9}$ As shown in the literature, the ORR activity of $\mathrm{Ag}$ is about an order of magnitude lower than that of Pt due to the low d-band centre and filled d band of Ag. ${ }^{74}$ Moreover, the catalytic 
performance could be affected by the surfactant poly(vinyl alcohol) (PVA), which is difficult to remove completely from the surface of the catalyst (Fig. S3†). An example of similar effects on the ORR caused by surfactants was reported by $\mathrm{Lu}$ et al., and they found that the ORR current density of the Ag nanorods was significantly increased after the surfactant was removed from the material surface. ${ }^{75}$ Therefore, the intrinsic ORR activity of our samples is likely to be a bit higher if the surfactants are completely removed. The surfactant removal is a complicated procedure that could influence the physical and chemical parameters of the materials, which might be a matter of a separate study. ${ }^{76}$ Therefore, to minimize the systematic uncertainty in the experiment, we perform a similar post-irradiation treatment for all the samples in the current work.

The Tafel plots, used for further analysis of the ORR kinetics of all catalysts, are presented in Fig. 7e. The Tafel slope values decrease in the following sequence: $\mathrm{Ag}>\mathrm{Ag} @ \mathrm{NiO} \approx \mathrm{Ag} /$ $\mathrm{Ni}>\mathrm{Pt} / \mathrm{C}$, and are in the range from -80 to $-100 \mathrm{mV} \mathrm{dec}{ }^{-1}$ for all Ag-based samples. Since the slope values will be different if different potential ranges are used for data analysis, there is still a debate about how to interpret the Tafel slope trends for the kinetics of oxygen reduction. ${ }^{73}$ However, considering the values of the potential range shown in Fig. 7e and comparing them to the values reported in the literature (from -80 to $\left.-120 \mathrm{mV} \mathrm{dec}{ }^{-1}\right),{ }^{77-80}$ we may assume that the slow transfer of the first electron to the $\mathrm{O}_{2}$ molecule could be a rate-determining step (RDS) for the ORR process for all three Ag-based samples presented in the current study.

From the point of view of practical applications, in addition to superior activity, catalysts should possess good stability under operating conditions. The chronoamperometry (CA) method was used to evaluate and compare the stability of the two types of bimetallic Ag-Ni samples. As seen in Fig. 7f, $\mathrm{Ag} / \mathrm{Ni}$ showed good stability with only $4.8 \%$ current decay after 20 hours at $0.65 \mathrm{~V}$ in $\mathrm{O}_{2}$-saturated $0.1 \mathrm{M} \mathrm{KOH}$, which is around 4 times lower than that of Ag@NiO (19.5\% decay). The atomic ratio of the constituents of two bimetallic Ag-Ni samples was determined by inductively coupled plasma optical emission spectroscopy (ICP-OES) before and after the electrochemical stability test (Table $\mathrm{S} 5 \dagger$ ). The $\mathrm{Ag}$-to-Ni ratio in the $\mathrm{Ag} / \mathrm{Ni}$ samples is found to be $3: 1$ before and after the test, while in the Ag@NiO samples it changes from $\mathrm{Ag}_{4} \mathrm{Ni}_{1}$ to $\mathrm{Ag}_{4.5} \mathrm{Ni}_{1}$ under the same test conditions.

\section{Discussion}

The electrochemical studies reveal that both bimetallic $\mathrm{Ag}-\mathrm{Ni}$ and monometallic Ag catalysts demonstrate a pseudo four-electron transfer pathway. The bimetallic $\mathrm{Ag}-\mathrm{Ni}$ nanocatalysts show an enhanced specific activity compared to both pure Ag and $\mathrm{Ni}$ catalysts. Evidently, the modulation of the catalysts' structures carried out in the current study is the main reason for the enhanced electrochemical performance. Although the electrochemical parameters measured for both bimetallic samples are quite close to each other, the reasons behind the enhanced ORR activity may be different.

As shown above, core-shell Ag@NiO consists of metallic Ag nanoparticles covered by the amorphous NiO layers. The interactions at the Ag-Ni interfaces imply changes in the atomic surrounding, which leads to either partial alloying or the formation of new structures, like mixed oxide $\mathrm{Ag}-\mathrm{Ni}-\mathrm{O}$. The introduced modifications of the electronic structure of the constituents may lead to a ligand effect, which would accelerate the charge transfer between $\mathrm{Ag}$ and $\mathrm{NiO}$, thus changing the interfacial chemical properties. Since the Ni-based shell layers are amorphous, the introduced $\mathrm{Ag}$ lattice strain at the interfaces is negligible. However, the individual atoms around the interface may still experience a strain-like environment and therefore display a different activity from a crystalline film, as has been observed on Pt in acidic solution. ${ }^{81}$ Besides, an amorphous film will have very different interactions with species on the surface as compared to a crystalline one, which can affect the rate of catalytic reactions. To sum up, in the Ag@NiO sample, both electronic effects are assumed to contribute to the improved ORR activity, while the strong ligand effect induced by the amorphous $\mathrm{Ni}-\mathrm{O}$ layers may play a prominent role.

Heterostructured $\mathrm{Ag} / \mathrm{Ni}$, as revealed by the structural analysis, contain clusters of metallic Ni covered by Ni (oxy-hydro) oxides. These clusters are attached to the surface of the $\mathrm{Ag}$ nanoparticles. Since both Ag and Ni-based clusters are crystalline, they may grow epitaxially with respect to each other. The large lattice mismatch, of about $11 \%$, established between $\mathrm{Ag}$ and the $\mathrm{Ni}_{2} \mathrm{O}_{3} / \mathrm{NiOOH}$ (oxy-hydro) oxides may result in a tensile lattice strain of the silver surface layers which, in turn, leads to changes in the electronic structure of Ag. Note that an interface-induced ligand effect in the $\mathrm{Ag} / \mathrm{Ni}$ sample would also contribute to the catalytic performance even though the interface sites are disrupted. Moreover, a high-valence $\mathrm{Ni}(\geq 2)$ with even fewer d-electrons forming in an $\mathrm{Ag} / \mathrm{Ni}$ sample would imply changes in the electronic structure of metal-adsorbate type and, thus, might also contribute to the enhanced ORR activity. ${ }^{82}$ The latter would need a detailed investigation that is beyond the scope of the present study. Therefore, in the $\mathrm{Ag} / \mathrm{Ni}$ sample, the improved ORR activity could also be attributed to a cumulative effect of both the ligand and strain effects. Because of the large lattice mismatch between $\mathrm{Ag}$ and the $\mathrm{Ni}$ (oxy-hydro) oxides, the strain effect may be considered as a dominant contribution to the activity enhancement.

The superior ORR stability of heterostructured $\mathrm{Ag} / \mathrm{Ni}$ as compared to core-shell Ag@NiO, could be ascribed to the possible presence of a stable crystalline $\mathrm{NiOOH}$ compound in the former. As confirmed by ICP-OES, the Ag-to-Ni atomic ratio in the $\mathrm{Ag} / \mathrm{Ni}$ sample does not change before and after the stability test. However, in the Ag@NiO sample, it changes from $\mathrm{Ag}_{4} \mathrm{Ni}_{1}$ to $\mathrm{Ag}_{4.5} \mathrm{Ni}_{1}$ under the same test conditions, indicating that some of the Ni ions are lost. This result is consistent with the findings reported by Back et al., where the authors claimed that the presence of a stable $\mathrm{NiOOH}$ compound results in the enhanced stability of the catalyst for the ORR. ${ }^{31}$ 


\section{Conclusions}

Two types of bimetallic silver-nickel (Ag-Ni) nanocatalysts, core-shells (Ag@NiO) and heterostructures (Ag/Ni), have been fabricated for the first time using $\gamma$-radiation induced reduction.Ag@NiO consists of an amorphous Ni oxide layer of about $2 \mathrm{~nm}$ thickness as a shell, and a faceted Ag particle as a core. Meanwhile Ag/Ni comprise polycrystalline Ni-based clusters adjacent to the surface of metallic Ag particles. The composition of the clusters corresponds to metallic $\mathrm{Ni}$ covered with $\mathrm{Ni}$ (oxy-hydro) oxides, $\mathrm{Ni}(\mathrm{OH})_{2} / \mathrm{Ni}_{2} \mathrm{O}_{3} / \mathrm{NiOOH}$. Electrochemical analysis reveals that both materials proceed with a pseudo four-electron transfer pathway and show a similar but increased alkaline ORR activity compared to monometallic catalysts. The enhanced ORR activity of the core-shell $\mathrm{Ag} @ N i O$ nanoparticles is attributed mainly to a ligand effect originating from the changing atomic surroundings at the $\mathrm{Ag}$ $\mathrm{Ni}$ interfaces. In contrast, the strong strain of about $11 \%$, arising from the significant lattice mismatch between the $\mathrm{Ni}$ (oxy-hydro) oxides and $\mathrm{Ag}$, is mainly responsible for the enhanced activity of the $\mathrm{Ag} / \mathrm{Ni}$ catalyst. The comparative study of two different types of nanocatalysts enables us to resolve the contributions of the ligand and strain effects on the activity of the $\mathrm{Ag}-\mathrm{Ni}$ catalysts. ${ }^{30}$ In addition, due to the existence of the stable $\mathrm{Ni}^{3+}$ compounds $\left(\mathrm{Ni}_{2} \mathrm{O}_{3} / \mathrm{NiOOH}\right)$ on their surfaces, $\mathrm{Ag} / \mathrm{Ni}$ exhibit good stability under operating conditions.

The findings presented in the current study demonstrate, among others, the advantages of using $\gamma$-radiation induced approaches for the engineering of bimetallic nanocatalysts with a well-defined interfacial structure. The results presented in this study can be used as the starting point for optimizing the morphology, composition, and structure of Ag-Ni nanocatalysts to achieve their characteristics suitable for industrial use. Due to their special structure and composition, the obtained Ag-Ni nanomaterials can potentially be used as effective catalysts for the peroxide electroreduction and oxygen evolution reaction.

\section{Experimental}

\section{Chemicals}

$\mathrm{Ag}$ nitrate, $\mathrm{AgNO}_{3}(\geq 99.0 \%)$, nickel(II) acetate tetrahydrate, Ni $\left(\mathrm{CH}_{3} \mathrm{COO}\right)_{2} \cdot 4 \mathrm{H}_{2} \mathrm{O}$ (98\%), poly(vinyl alcohol), $\left[-\mathrm{CH}_{2} \mathrm{CHOH}^{-}\right]_{n}$ (PVA, $\quad M_{\mathrm{W}} \quad 70000, \quad 87-90 \%$ hydrolyzed), propan-2-ol, $\left(\mathrm{CH}_{3}\right)_{2} \mathrm{CHOH}$ (IPA, 99.9\%), potassium hydroxide, $\mathrm{KOH}$ (pellets, $99.99 \%)$, lead(II) nitrate, $\mathrm{Pb}\left(\mathrm{NO}_{3}\right)_{2}$ (99.999\%), potassium chloride solution $\mathrm{KCl}$ solution (for $\mathrm{Ag} / \mathrm{AgCl}$ electrodes, $\sim 3 \mathrm{M} \mathrm{KCl}$, saturated with silver chloride $(\sim 0.16 \mathrm{M} \mathrm{AgCl}))$, and Nafion-117 ( $5 \%$ in a mixture of lower aliphatic alcohols and water) were purchased from Sigma Aldrich. Milli-Q water (Millipore, 18.2 $\mathrm{M} \Omega \mathrm{cm}$ at $25^{\circ} \mathrm{C}$ ) was used in all experiments.

\section{Synthesis of core-shell Ag@NiO}

Ag@NiO was prepared by a one-step $\gamma$-radiation induced synthesis method. A mixture of $5 \mathrm{mM} \mathrm{AgNO}_{3}, 5 \mathrm{mM} \mathrm{Ni}$
$\left(\mathrm{CH}_{3} \mathrm{COO}\right)_{2} \cdot 4 \mathrm{H}_{2} \mathrm{O}, 2 \mathrm{M}$ IPA and $1.0 \mathrm{wt} \%$ PVA was purged with $\mathrm{N}_{2}$ (99.999\% purity, Linde) for $30 \mathrm{~min}$ and sealed with a septum in a glass vial. The solution was then irradiated for 40 hours which corresponds to the total irradiation dose of 21.6 kGy. The obtained black suspension solution was centrifuged at $8000 \mathrm{rpm}$ for $15 \mathrm{~min}$, then washed with IPA/Milli-Q water three times and dispersed in IPA for further use.

\section{Synthesis of heterostructured $\mathrm{Ag} / \mathrm{Ni}$}

$\mathrm{Ag} / \mathrm{Ni}$ was synthesized by a successive reduction process. $\mathrm{Ni}$ nanoparticles in the form of a suspension were obtained first by $\gamma$-radiation induced reduction. The synthesis procedure is the same as that for the synthesis of Ag@NiO. The only difference is that $5 \mathrm{mM} \mathrm{Ni}\left(\mathrm{CH}_{3} \mathrm{COO}\right)_{2} \cdot 4 \mathrm{H}_{2} \mathrm{O}$ dissolved in water is used as a precursor. Thereafter, $1.5 \mathrm{~mL}$ of the $\mathrm{AgNO}_{3}$ stock solution (0.1 M) was injected dropwise into the sealed vial with a Ni suspension, and the concentration of $\mathrm{Ag}^{+}$in the suspension solution was $5 \mathrm{mM}$. The vial was then gently shaken and placed into the glovebox for 20 hours. The Ag/Ni precipitates were washed by centrifugation under the same conditions as described above and dispersed in IPA.

For comparison, monometallic $\mathrm{Ag}$ and $\mathrm{Ni}$ nanoparticles were synthesized by irradiating the aqueous solution of $\mathrm{AgNO}_{3}$ (20 hours) and $\mathrm{Ni}\left(\mathrm{CH}_{3} \mathrm{COO}\right)_{2} \cdot 4 \mathrm{H}_{2} \mathrm{O}$ (40 hours), respectively. The other experimental conditions remained unchanged. More detailed information about the synthesis is described in the ESI. $\dagger$

\section{Material characterization}

XRD patterns were recorded on a PANanalytical X'Pert PRO diffractometer with $\mathrm{CuK} \alpha$ radiation $(\lambda=1.5418 \AA)$. SAED patterns, and TEM, HRTEM, and HAADF-STEM images were obtained on FEI Tecnai G2 F20 equipped with energy dispersive X-ray spectrometry accessories. The composition of bimetallic samples, and the actual amount of metals on the glassy carbon (GC) electrode were determined by ICP-OES measurements with an iCAP 6000 series instrument (Thermo Fisher Scientific). XPS was performed with a PerkinElmer PHI 5000C ESCA system. Al K $\alpha$ radiation $(h \nu=1486.7 \mathrm{eV})$ was used as an excitation source, and the chamber pressure was kept below $6 \times 10^{-10}$ Torr. The binding energy of the spectra was calibrated at the $\mathrm{C} 1 \mathrm{~s}$ core level at $284.8 \mathrm{eV}$ from adventitious carbon. Characterization and analysis details of XPS and ICP-OES are described in the ESI. $\dagger$

\section{Electrochemical test}

The catalyst ink was prepared by mixing $10 \mu \mathrm{L}$ of Nafion-117 with a specific volume of the as-prepared nanoparticle dispersions. The metal concentration in the nanoparticle dispersions was measured by ICP-OES before the ink preparation. A specific volume of the ink $(10-20 \mu \mathrm{L})$ was taken with a pipette and cast on mirror polished GC electrodes with a surface area of $0.196 \mathrm{~cm}^{2}$. The electrodes were then dried in an ambient environment. The catalyst loadings were aimed at $70 \mu \mathrm{g}_{\mathrm{Ag}}$ $\mathrm{cm}^{-2}$ for the Ag-based catalysts (Ag, Ag@NiO and $\mathrm{Ag} / \mathrm{Ni}$ ), $15 \mu \mathrm{g}_{\mathrm{Pt}} \mathrm{cm}^{-2}$ for commercial $\mathrm{Pt} / \mathrm{C}$ and $250 \mu \mathrm{g}_{\mathrm{Ni}} \mathrm{cm}^{-2}$ for the $\mathrm{Ni}$ 
sample. The actual amount of the catalyst on modified GC was quantified by ICP-OES as well. All electrochemical measurements were performed in a three-electrode system using a potentiostat (BioLogic SP-300) with a graphite rod as a counter electrode and $\mathrm{Ag} / \mathrm{AgCl}$ in saturated $\mathrm{KCl}$ solution as a reference electrode. According to the $i R$-compensation instructions and suggestions by BioLogic, all the potentials reported here were corrected with $85 \%$ iR-compensation and calibrated to a reversible hydrogen electrode (RHE) according to $E(\mathrm{RHE})=$ $E(\mathrm{Ag} / \mathrm{AgCl})+0.964 \mathrm{~V}$ in $0.1 \mathrm{M} \mathrm{KOH}$. Before the ORR activity test, the catalysts were activated with $\mathrm{CV}$ for 20-50 cycles at $50 \mathrm{mV} \mathrm{s}^{-1}$. A potential at which the current density exceeds a threshold value of $0.1 \mathrm{~mA} \mathrm{~cm} \mathrm{~cm}^{-2}$ was used to determine the $E_{\text {onset }}{ }^{83}$ Reproducibility tests with the same experimental procedures were conducted on each sample 3 times to avoid any chances of serendipity.

\section{Conflicts of interest}

There are no conflicts to declare.

\section{Acknowledgements}

The authors would like to acknowledge the Swedish Foundation for Strategic Research, SSF (Grant EM16-0060) for the financial support of the current study. B. W. thanks the Swedish Research Council (Project No. 2018-03927). In addition, Y. Y. acknowledges Jai Leslie White (Applied Electrochemistry, KTH) and Ceshigou Research Service for help with samples characterizations.

\section{References}

1 S. Gottesfeld, D. R. Dekel, M. Page, C. Bae, Y. Yan, P. Zelenay and Y. S. Kim, J. Power Sources, 2018, 375, 170184.

2 A. Sarapuu, E. Kibena-Põldsepp, M. Borghei and K. Tammeveski, J. Mater. Chem. A, 2018, 6, 776-804.

3 D. R. Dekel, J. Power Sources, 2018, 375, 158-169.

4 United States Geological Survey (USGS), Mineral Commodity Summaries 2020, 2020.

5 J. Guo, A. Hsu, D. Chu and R. Chen, J. Phys. Chem. C, 2010, 114, 4324-4330.

$6 \mathrm{H}$. Erikson, A. Sarapuu and K. Tammeveski, ChemElectroChem, 2019, 6, 73-86.

7 J. M. Linge, D. Kozhemyakin, H. Erikson, S. Vlassov, N. Kongi and K. Tammeveski, ChemCatChem, 2021, 13, 4364-4371.

8 M. Chatenet, L. Genies-Bultel, M. Aurousseau, R. Durand and F. Andolfatto, J. Appl. Electrochem., 2002, 32, 11311140.

9 A. Qaseem, F. Chen, X. Wu and R. L. Johnston, Catal. Sci. Technol., 2016, 6, 3317-3340.
10 A. Holewinski, J. C. Idrobo and S. Linic, Nat. Chem., 2014, 6, 828-834.

11 F. H. B. Lima, J. Zhang, M. H. Shao, K. Sasaki, M. B. Vukmirovic, E. A. Ticianelli and R. R. Adzic, J. Phys. Chem. C, 2007, 111, 404-410.

12 S. A. Park, H. Lim and Y. T. Kim, ACS Catal., 2015, 5, 39954002.

13 A. J. Appleby, Catal. Rev., 1971, 4, 221-244.

14 Z. Xu, X. Zhang, X. Wang, J. Fang, Y. Zhang, X. Liu, W. Zhu, Y. Yan and Z. Zhuang, ACS Nano, 2021, 15, 7131-7138.

15 S. De, J. Zhang, R. Luque and N. Yan, Energy Environ. Sci., 2016, 9, 3314-3347.

16 Y. Yang, L. M. Luo, Y. F. Guo, Z. X. Dai, R. H. Zhang, C. Sun and X. W. Zhou, J. Electroanal. Chem., 2016, 783, 132-139.

17 R. Majee, A. Kumar, T. Das, S. Chakraborty and S. Bhattacharyya, Angew. Chem., Int. Ed., 2020, 59, 28812889.

18 Z. Zhang, T. M. Nenoff, J. Y. Huang, D. T. Berry and P. P. Provencio, J. Phys. Chem. C, 2009, 113, 1155-1159.

19 D. Bonventre, E. Panizon and R. Ferrando, Part. Part. Syst. Charact., 2018, 35, 1700425.

20 G. Rossi, A. Rapallo, C. Mottet, A. Fortunelli, F. Baletto and R. Ferrando, Phys. Rev. Lett., 2004, 93, 105503.

21 A. Rapallo, G. Rossi, R. Ferrando, A. Fortunelli, B. C. Curley, L. D. Lloyd, G. M. Tarbuck and R. L. Johnston, J. Chem. Phys., 2005, 122, 194308.

22 I. Parsina and F. Baletto, J. Phys. Chem. C, 2010, 114, 15041511.

23 E. Panizon and R. Ferrando, Nanoscale, 2016, 8, 1591115919.

24 K. D. Jensen, J. Tymoczko, J. Rossmeisl, A. S. Bandarenka, I. Chorkendorff, M. Escudero-Escribano and I. E. L. Stephens, Angew. Chem., Int. Ed., 2018, 57, 28002805.

25 M. T. Gorzkowski and A. Lewera, J. Phys. Chem. C, 2015, 119, 18389-18395.

26 K. A. Kuttiyiel, K. Sasaki, G. G. Park, M. B. Vukmirovic, L. Wu, Y. Zhu, J. G. Chen and R. R. Adzic, Chem. Commun., 2017, 53, 1660-1663.

27 D. Bhalothia, P.-C. Chen, C. Yan, K.-W. Wang and T.-Y. Chen, J. Phys. Chem. C, 2020, 124, 2295-2306.

28 S. A. Park, E. K. Lee, H. Song and Y. T. Kim, Sci. Rep., 2015, 5, 1-14.

29 M. Mavrikakis, B. Hammer and J. K. Nørskov, Phys. Rev. Lett., 1998, 81, 2819-2822.

30 J. R. Kitchin, J. K. Nørskov, M. A. Barteau and J. G. Chen, Phys. Rev. Lett., 2004, 93, 156801.

31 S. Back, M. H. Hansen, J. A. Garrido Torres, Z. Zhao, J. K. Nørskov, S. Siahrostami and M. Bajdich, ACS Appl. Mater. Interfaces, 2019, 11, 2006-2013.

32 J. Grand, S. R. Ferreira, V. De Waele, S. Mintova and T. M. Nenoff, J. Phys. Chem. C, 2018, 122, 12573-12588.

33 S. M. Ghoreishian, S. M. Kang, G. Seeta Rama Raju, M. Norouzi, S. C. Jang, H. J. Yun, S. T. Lim, Y. K. Han, C. Roh and Y. S. Huh, Chem. Eng. J., 2019, 360, 1390-1406. 34 H. A. Schwarz, J. Chem. Educ., 1981, 58, 101-105. 
35 A. J. Swallow, Int. J. Radiat. Biol. Relat. Stud. Phys., Chem. Med., 1976, 30, 399-399.

36 H. A. Schwarz and R. W. Dodson, J. Phys. Chem., 1989, 93, 409-414.

37 J. Belloni, M. Mostafavi, H. Remita, J. L. Marignier and M. O. Delcourt, New J. Chem., 1998, 22, 1239-1255.

38 Y. Yang, M. Johansson, A. Wiorek, N. V. Tarakina, F. Sayed, R. Mathieu, M. Jonsson and I. L. Soroka, Dalton Trans., 2021, 50, 376-383.

39 J. Belloni, Catal. Today, 2006, 113, 141-156.

40 M. Mostafavi, N. Keghouche, M. O. Delcourt and J. Belloni, Chem. Phys. Lett., 1990, 167, 193-197.

41 M. Tsuji, S. Hikino, M. Matsunaga, Y. Sano, T. Hashizume and H. Kawazumi, Mater. Lett., 2010, 64, 1793-1797.

42 M. Treguer, C. De Cointet, H. Remita, J. Khatouri, M. Mostafavi, J. Amblard, J. Belloni and R. De Keyzer, J. Phys. Chem. B, 1998, 102, 4310-4321.

43 K. V. Manukyan, W. Tan, R. J. Deboer, E. J. Stech, A. Aprahamian, M. Wiescher, S. Rouvimov, K. R. Overdeep, C. E. Shuck, T. P. Weihs and A. S. Mukasyan, ACS Appl. Mater. Interfaces, 2015, 7, 11272-11279.

44 W. Zhou, X. Cao, Z. Zeng, W. Shi, Y. Zhu, Q. Yan, H. Liu, J. Wang and H. Zhang, Energy Environ. Sci., 2013, 6, 22162221.

45 K. Kobayashi, Phys. Rev. B: Condens. Matter Mater. Phys., 1996, 53, 11091-11099.

46 E. R. Jette and F. Foote, J. Chem. Phys., 1935, 3, 605-616.

47 W. Beesk, P. G. Jones, H. Rumpel, E. Schwarzmann and G. M. Sheldrick, J. Chem. Soc., Chem. Commun., 1981, 664665.

48 S. S. Kabalkina, S. V. Popova, N. R. Serebryanaya and L. F. Vereshchagin, Dokl. Akad. Nauk SSSR, 1963, 152, 853-854.

49 U. Wedig, P. Adler, J. Nuss, H. Modrow and M. Jansen, Solid State Sci., 2006, 8, 753-763.

50 P. S. Aggarwal and A. Goswami, J. Phys. Chem., 1961, 65, 2105-2105.

51 A. Taylor, J. Inst. Met., 1950, 77, 585-594.

52 J. D. Hanawalt, H. W. Rinn and L. K. Frevel, Ind. Eng. Chem., Anal. Ed., 1938, 10, 457-512.

53 G. Schön, J. Tummavuori, B. Lindström, C. R. Enzell, C. R. Enzell and C.-G. Swahn, Acta Chem. Scand., 1973, 27, 2623-2633.

54 S. Lv, F. Yang, X. Chu, H. Wang, J. Yang, Y. Chi and X. Yang, Metals, 2019, 9, 826.

55 F. Bao, F. Tan, W. Wang, X. Qiao and J. Chen, RSC Adv., 2017, 7, 14283-14289.

56 K. S. Kim and N. Winograd, Surf. Sci., 1974, 43, 625-643.

57 P. Dubey, N. Kaurav, R. S. Devan, G. S. Okram and Y. K. Kuo, RSC Adv. , 2018, 8, 5882-5890.

58 P. T. Andrews, T. Collins and P. Weightman, J. Phys. C: Solid State Phys., 1981, 14, L957.

59 B. P. Payne, M. C. Biesinger and N. S. McIntyre, J. Electron Spectrosc. Relat. Phenom., 2009, 175, 55-65.

60 M. C. Biesinger, B. P. Payne, A. P. Grosvenor, L. W. M. Lau, A. R. Gerson and R. S. C. Smart, Appl. Surf. Sci., 2011, 257, 2717-2730.
61 A. P. Grosvenor, M. C. Biesinger, R. S. C. Smart and N. S. McIntyre, Surf. Sci., 2006, 600, 1771-1779.

62 D. A. Svintsitskiy, M. K. Lazarev, T. Y. Kardash, E. A. Fedorova, E. M. Slavinskaya and A. I. Boronin, J. Chem. Phys., 2020, 152, 044707.

63 J. Liu, J. Liu, W. Song, F. Wang and Y. Song, J. Mater. Chem. A, 2014, 2, 17477-17488.

64 L. Yuan, L. Jiang, J. Liu, Z. Xia, S. Wang and G. Sun, Electrochim. Acta, 2014, 135, 168-174.

65 J. Wang, Q. Zhao, H. Hou, Y. Wu, W. Yu, X. Ji and L. Shao, RSC Adv., 2017, 7, 14152-14158.

66 M. Alsabet, M. Grdeń and G. Jerkiewicz, Electrocatalysis, 2015, 6, 60-71.

67 J. H. Stenlid and T. Brinck, J. Am. Chem. Soc., 2017, 139, 11012-11015.

68 R. Subbaraman, D. Tripkovic, K. C. Chang, D. Strmcnik, A. P. Paulikas, P. Hirunsit, M. Chan, J. Greeley, V. Stamenkovic and N. M. Markovic, Nat. Mater., 2012, 11, 550-557.

69 F. J. Vidal-Iglesias, R. M. Arán-Ais, J. Solla-Gullón, E. Herrero and J. M. Feliu, ACS Catal., 2012, 2, 901910.

70 J. M. Linge, H. Erikson, J. Kozlova, J. Aruväli, V. Sammelselg and K. Tammeveski, J. Solid State Electrochem., 2018, 22, 81-89.

71 Z. Li, Y. Yang, A. Relefors, X. Kong, G. M. Siso, B. Wickman, Y. Kiros and I. L. Soroka, J. Colloid Interface Sci., 2021, 583, 71-79.

72 C. Wei, S. Sun, D. Mandler, X. Wang, S. Z. Qiao and Z. J. Xu, Chem. Soc. Rev., 2019, 48, 2518-2534.

73 L. Tammeveski, H. Erikson, A. Sarapuu, J. Kozlova, P. Ritslaid, V. Sammelselg and K. Tammeveski, Electrochem. Commun., 2012, 20, 15-18.

74 S. Gu, W. Sheng, R. Cai, S. M. Alia, S. Song, K. O. Jensen and Y. Yan, Chem. Commun., 2013, 49, 131-133.

75 Y. Lu, Y. Wang and W. Chen, J. Power Sources, 2011, 196, 3033-3038.

76 Z. Niu and Y. Li, Chem. Mater., 2014, 26, 72-83.

77 J. M. Linge, H. Erikson, A. Kasikov, M. Rähn, V. Sammelselg and K. Tammeveski, Electrochim. Acta, 2019, 325, 134922.

78 J. M. Linge, H. Erikson, M. Merisalu, L. Matisen, M. Käärik, J. Leis, V. Sammelselg, J. Aruväli, T. Kaljuvee and K. Tammeveski, J. Electrochem. Soc., 2018, 165, F1199F1205.

79 B. B. Blizanac, P. N. Ross and N. M. Marković, J. Phys. Chem. B, 2006, 110, 4735-4741.

80 D. Šepa, M. Vojnovíc and A. Damjanovic, Electrochim. Acta, 1970, 15, 1355-1366.

81 Q. Wang, F. Chen, Y. Liu, N. Zhang, L. An and R. L. Johnston, ACS Appl. Mater. Interfaces, 2017, 9, 3570135711.

82 X. Zhao, X. Liu, B. Huang, P. Wang and Y. Pei, J. Mater. Chem. A, 2019, 7, 24583-24593.

83 W. Xia, A. Mahmood, Z. Liang, R. Zou and S. Guo, Angew. Chem., Int. Ed., 2016, 55, 2650-2676. 